\title{
CAPÍTULO 12: EXPERIÊNCIAS DE UMA HACKATHON REMOTA EM MEIO À PANDEMIA DA COVID-19
}

\section{CAPÍTULO 12: EXPERIENCIAS DE UNA HACKATHON REMOTA EN MEDIO A LA PANDEMIA DE LA COVID-19}

\section{CHAPTER 12: EXPERIENCES OF A REMOTE HACKATHON DURING COVID-19 PANDEMIC}

Guilherme de Siqueira Freitas Pontes ${ }^{1}$; Mariana Xavier de Mesquita Santos²; Misael Tomaz de Araújo ${ }^{3}$; Pablo Vinicius do Nascimento Pinto ${ }^{4}$; Simone de Paula Silva ${ }^{5}$

DOI: https://doi.org/10.31692/978-65-88970-03-4.188-192

\section{INTRODUÇÃO}

Este trabalho traz uma experiência ocorrida no ano de 2020, no evento online chamado "Hacking.Help 2020." A maratona foi organizada pela Ions Innovation, em paceria com intiuições de Ensino Superior do Rio de Janeiro. Com este espírito, alunos de nível superior e técnico de diversas instituições do Brasil e demais países de língua lusófona participaram, durante um fim de semana de uma atividade. Tal proposta de desenvolvimento estudantil foi adaptada para a versão digital, que representa uma das transformações ocasionadas pelos efeitos da pandemia do Novo Coronvavírus.

A principal proposta foi do grupo foi a criação de uma alternativa remota de empregablidade para recém-formados em seu ingresso no mercado de trabalho em meio a pandemia do COVID-19. O relato de experiência a ser desenvolvido objetiva ao detalhamento do que foi realizado pelos estudantes em tal maratona.

\section{RELATO DE EXPERIÊNCIA}

As atividades de extensão representam uma função determinante no destino de uma sociedade (RODRIGUES, 2013). Sendo assim, considera-se o HackingHelp um projeto com intuito de discutir soluções inovadoras em clusters e desafios como empregabilidade, educação, logística, cooperativismo, assistência social e saúde (ANPROTEC, 2020) prevê incrementos ao escopo social no qual se faz existir.

${ }^{1}$ Gestão de Turismo, Instituto Federal de Pernambuco, guilhermesfpontes@gmail.com

${ }^{2}$ Gestão de Turismo, Instituto Federal de Pernambuco, marianaxaviermesquita@ gmail.com

${ }^{3}$ Sistemas de Informação, Universidade Federal Rural de Pernambuco, misaelta.contato@ gmail.com

${ }^{4}$ Fonoaudiologia, Universidade Católica de Pernambuco, pabloviniciusdonp@gmail.com

${ }^{5}$ Mestra em Gestão Ambiental, Instituto Federal de Pernambuco, simonedypaula@gmail.com

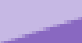


O evento ocorreu no modelo de uma Hackathon, que segundo Guizardi, Santos, Lemos e Severo (2018), palavra "hackathon" vem da combinação das palavras "hack" e "marathon" e tempo significado uma corrida para criar algo útil em um só evento. As autoras (2018) explicam que o evento emergiu na área de tecnologia buscando engajar diferentes profissionais em um trabalho colaborativo, de natureza intensiva, realizado em curto período de tempo e com foco em determinado desafio.

Os estudantes participantes da equipe ReckTonPDV, mediante consenso, escolheram a área de empregabilidade e, dentre os desafios apresentados, buscou-se uma forma de reinserir e capacitar profissionais afetados pela pandemia do Novo Coronavírus (UOL, 2020). Deste modo, foi desenvolvida uma plataforma em website para fomentar e auxiliar os candidatos na busca de requalificação profissional, conforme o desafio a seguir. Visando facilitar a interação entre empresas e trabalhadores, respectivamente (JORNAL CONTABIL, 2017), o sitio virtual Match, linkando empresas e candidatos se descreve da seguinte maneira. Serão expostos os resumos do desafio e da plataforma:

"Como criar um mecanismo de match de vagas em aberto para que esses profissionais possam se recolocar no mercado de trabalho nesse momento, mesmo que seja em trabalho remoto ou home office?"

"Uma plataforma virtual, na qual pessoas se candidatam a uma vaga de emprego e, ao mesmo tempo, empresas procuram candidatos ideais para aquela oportunidade”.

Além de aprimorar o contato entre profissionais e organizações, também foi idealizado pela equipe um conjunto de cursos nos quais os candidatos podem se preparar e qualificar, visando à melhora no seu currículo pessoal. Desta maneira, quanto mais seu currículo atender às expectativas, maiores são as chances de reinserção no mercado.

Figura 1: logomarca desenvolvida.

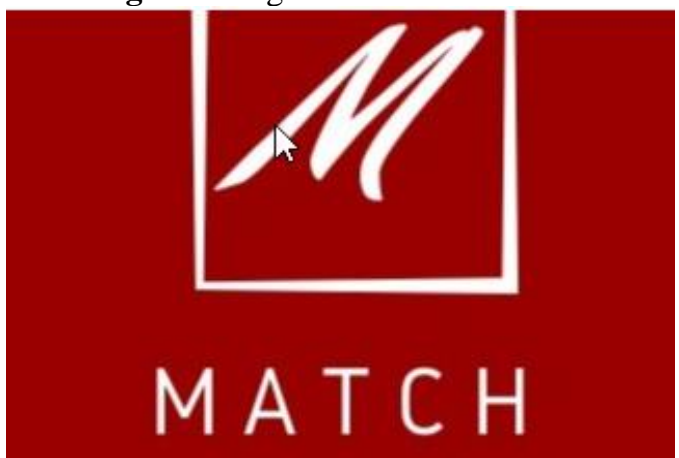

EMPRESA \& CANDIDATOS

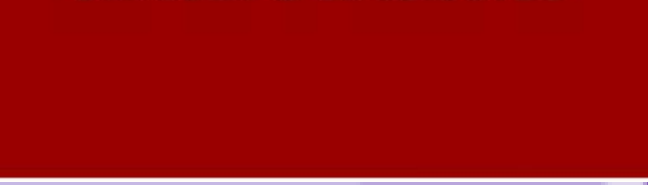

Fonte: Pinto (2020). 
Figura 2: Print de login da plataforma Match.
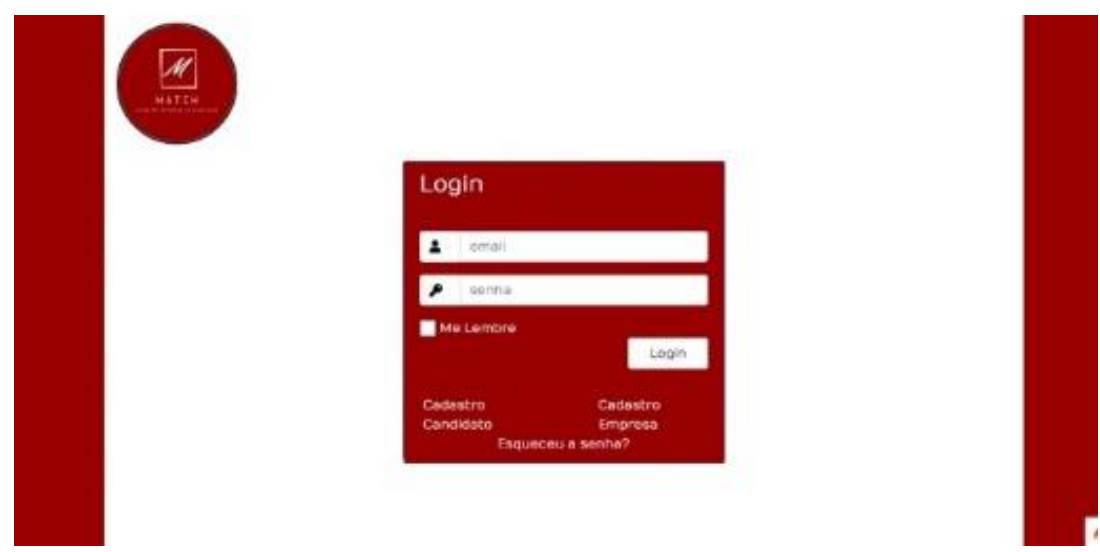

Fonte: Araújo (2020).

Figura 3: detalhes da plataforma Match.

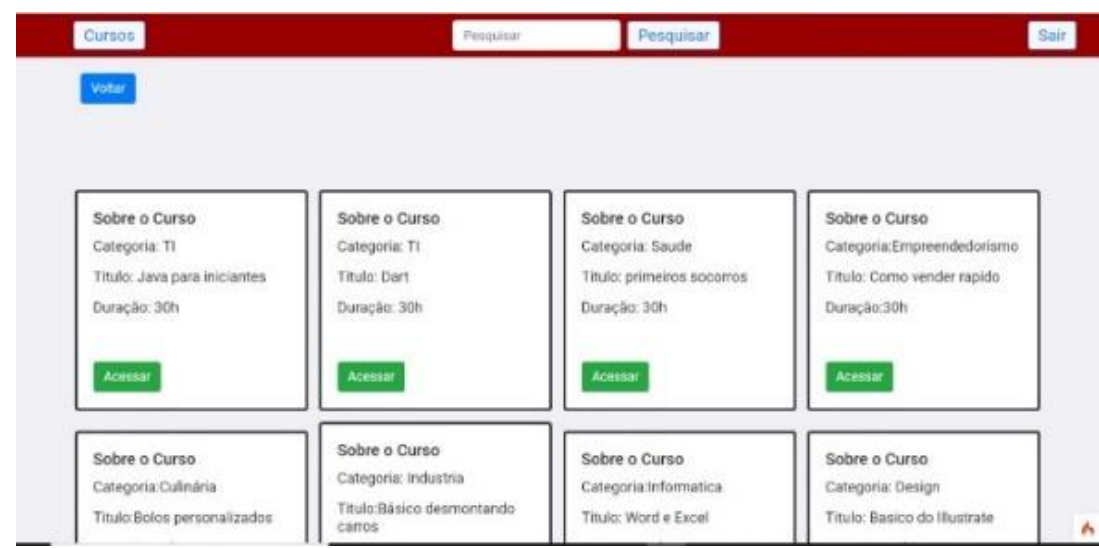

Fonte: Araújo (2020).

A atividade de extensão desempenhada auxiliou na compreensão da situação pandêmica e sobre a importância do trabalho em equipe, o qual desenvolve sentimentos de liderança e compartilhamento do saber (RIESS, 2010). $\quad$ O trabalho docente, explica Gondim (2001), mostra-se necessário, mesmo com o advento da tecnologia, para auxiliar no desenvolvimento estudantil.

O grupo composto por dois estudantes de Gestão de Turismo, um de Sistemas de Informação e um de Fonoaudiologia recebeu importantes mentorias de uma professora Mestra em Gestão Ambiental.

Os estudantes são de cursos de áreas distintas, como Gestão, TI e Saúde participaram do projeto, alguns participando pela primeira vez de uma Hackathon. Foi desafiador lidar com pressão, porém gratificante poder atuar em um projeto visando soluções em tempos de pandemia. Além disso, oautor do curso de Fonoaudiologia relata que durante o evento pode compreender o funcionamento da linguagem tecnológica e compreensão da importância de 
meios de comunicação online para o fazer profissional. A autora do curso de Gestão de Turismo sentiu-se desafiada ao grafar o pitch em curto espaço de tempo, porém pontuou como gratificante. $\mathrm{O}$ estudante de Gestão de Turismo demonstrou entusiasmo ao estudar mais sobre o momento pandêmico. Já o autor oriundo do curso de Sistemas de Informação descreveu como motivador criar uma plataforma nova em pouco espaço de tempo. Quanto à principal mentora da equipe, a docente pôde mentorar profissionais de distintas áreas do saber com o desafio recompensador de atuar em um evento cem por cento online. Para todos, o evento proporcionou aumento da rede de contatos.

\section{CONCLUSÕES}

Participar de uma hackaton é um desafio, visto que propor soluções inovadoras e tecnológicas, a serem colocadas em prática não é tarefa simples. Atuar com pesquisa, em grupo e em cenário de mudanças na sociedade foi uma quebra de paradigmas, visto à pouca existência prévia de eventos como o Hacking Help Rio. Foi possível desenvolver habilidades disruptivas durante o evento, além de propor reais mudanças na sociedade. Desta forma, é válido entender que os câmbios são possíveis mediante dedicação e respeito às diferenças presentes em novos tempos marcados pelas desigualdades ampliadas com um cenário pandêmico.

\section{REFERÊNCIAS}

ANPROTEC. Anprotec apoia o Hacking Help 2020 em busca de soluções que minimizem os efeitos da COVID-19. Disponível em: <https://anprotec.org.br/site/2020/05/anprotecapoia-o-hacking-help-2020-em-busca-de-solucoes-que-minimizem-os-efeitos-da-covid-19/> . $\begin{array}{llllll}\text { Acesso } & \text { em } & 17 & \text { de } & \text { setembro } & \text { de }\end{array}$

AYRES, M. Taxa de desemprego no Brasil pode até dobrar por coronavírus, diz Salim. Disponível em: < https://economia.uol.com.br/noticias/reuters/2020/04/30/taxa-dedesemprego-no-brasil-pode-ate-dobrar-por-coronavirus-diz-salim.htm/>. Acesso em 17 de setembro de 2020.

GONDIM, S.M.G. Trabalho docente e valores: em questão as novas tecnologías de informação e comunicação. São Paulo: Estud. psicol., v. 18, n. 1, p. 46-57, Apr. 2001.

GUIZARDI, F.L; SANTOS, K.G; LEMOS, A.S.P; SEVERO, F.M.D . Maratonas hackers no Brasil com desafios no campo da Saúde. São Paulo: Interface (Botucatu), 2018.

QUEIROZ, C.S. Trabalho em grupo traz benefícios para o aprendizado. Disponível em: <https://revistaeducacao.com.br/2015/03/06/trabalho-em-grupo-traz-beneficios-para-o- 
aprendizado/>. Acesso em 17 de setembro de 2020.

RIESS, M.L.R. Trabalho em grupo: instrumento mediador de socialização e aprendizagem. 2010. Trabalho de Conclusão de curso (Licenciatura) - Faculdade de Educação da Universidade Federal do Rio Grande do Sul - FACED/UFRGS. Rio Grande do Sul, 2010.

RODRIGUES, A.L.L. et.al. Contribuições da extensão universitária na sociedade.

Alagoas: Caderno de Graduação - Ciências Humanas e Sociais, v.1, n.15, p.141-148, Mar. 2013. v. 1. p. 175-175, 2005. 